\title{
Biological and genetic aspects of experimental hybrids from species of the Phyllosoma complex (Hemiptera: Reduviidae: Triatominae)
}

\author{
José Alejandro Martínez-Ibarra/ ${ }^{+}$, Luz Verónica Ventura-Rodríguez, Karla Meillon-Isais, \\ Héctor Barajas-Martínez, Ricardo Alejandre-Aguilar', Patricia Lupercio-Coronel, \\ Gonzalo Rocha-Chávez ${ }^{2}$, Benjamín Nogueda-Torres ${ }^{1}$
}

\begin{abstract}
Área de Entomología Médica ${ }^{2}$ Departamento de Desarrollo Regional, Centro Universitario del Sur, Universidad de Guadalajara, A. P. 20 49000 Ciudad Guzmán, Jalisco, México 'Becario de COFAA, Escuela Nacional de Ciencias Biológicas, Instituto Politécnico Nacional, Carpio y Plan de Ayala, Colonia Casco de Santo Tomás, México, D. F.
\end{abstract}

The present work is a thorough investigation of the degree of reproductive isolation between Meccus mazzottii and Meccus longipennis, Meccus picturatus, Meccus pallidipennis and Meccus bassolsae, as well as between M. longipennis and M. picturatus. We examined fertility and segregation of morphological characteristics in two generations of hybrids derived from crosses between these species. The percentage of pairs with (fertile) offspring was highest in the set of crosses between $\mathrm{M}$. longipennis and $\mathrm{M}$. picturatus, and lowest between $\mathrm{M}$. mazzottii and M. picturatus. Most first-generation (F1) individuals from crosses involving M. mazzottii were morphologically similar to this species, while only F1 x F1 progeny of parental crosses between M. mazzottii and M. longipennis had offspring second generation that looked like M. mazzottii. The results indicate that different degrees of reproductive isolation apparently exist among the species of the Phyllosoma complex examined in this study. The biological evidence obtained in this study does not support the proposal that $\mathrm{M}$. longipennis and $\mathrm{M}$. picturatus are full species. It could indicate on the contrary, that both could be considered as subspecies of a single polytypic species. On the other hand, biological evidence supports the proposal that M. mazzottii is a full species.

Key words: Phyllosoma complex - reproductive isolation - hybrids - phylogenetic level

There are at least 34 species of triatomines in Mexico. Among these are the six species typically considered to be members of the Phyllosoma complex [Meccus pallidipennis (Stål), Meccus longipennis (Usinger), Meccus picturatus (Usinger), Meccus mazzottii (Usinger), Meccus bassolsae (Alejandre-Aguilar, Nogueda-Torres, Cortés-Jiménez, Jurberg, Galvão and Carcavallo), M. phyllosomus (Burmeister)]. Most of these species play a major role in the transmission of Trypanosoma cruzi Chagas to human populations. They are found in both domestic and wild ecotopes, have frequent domiciliated colonies, and often show high values in the entomological indexes used to monitor Chagas disease control programs (Vidal-Acosta et al. 2000, Salazar-Schettino et al. 2005, Martínez-Ibarra et al. 2008). These species have also been considered to be in a group with systematic problems. Recently, they were included in the genus Meccus, but this has been revalidated based on several morphological synapomorphies such as size (the largest size in the genus Triatoma), the extremely wide connexivum, the unusually prominent thoracic tubercles, and the width of the abdomen, which is about one third of the insect's total length. In addition, there are important

+Corresponding author: aibarra@cusur.udg.mx

Received 24 August 2007

Accepted 29 April 2008 differences in structures, as in the shape of Meccus and Triatoma testicles; therefore, it is possible to consider both in the taxon of genera (Carcavallo et al. 2000). These differences were found by Silva and Schreiber (1969) in four genera and 11 species, and Lent et al. (1994) revalidated the genus Mepraia Mazza, Gajardo \& Jörg.

Another systematic problem of this group is the very status of the species. Over 60 years ago, Mazzotti and Osorio (1942) and Mazzotti (1943) proposed a subspecies status, considering the low degree of reproductive isolation within the Phyllosoma complex for M. pallidipennis, M. picturatus and M. mazzottii, and based on a small number of crossing experiments. Unfortunately, both studies were incomplete, since the authors did not use $M$. longipennis (the second most widely distributed species, which is parapatric with two other complex species) (Fig. 1) (Martínez-Ibarra et al. 2001, Espinoza-Gómez et al. 2002, Magallón-Gastélum et al. 2006). Also, they used only the most widely distributed species of the complex (M. pallidipennis), which is sympatric with two species of the complex and parapatric with three other species of the complex (Fig. 1) (Espinoza-Gómez et al. 2002, Galvão et al. 2003, Cohen et al. 2006). Two decades later, Usinger et al. (1966) supported this proposition and added M. longipennis to the list. However, not a single cross was reported by the latter authors. Twenty-three years ago, Zárate et al. (1985) provided additional information on the relationships among the species of the Phyllosoma complex by conducting crosses between five species known to belong to the complex at that time. Unfortunately, they were unable to accomplish the experiments 


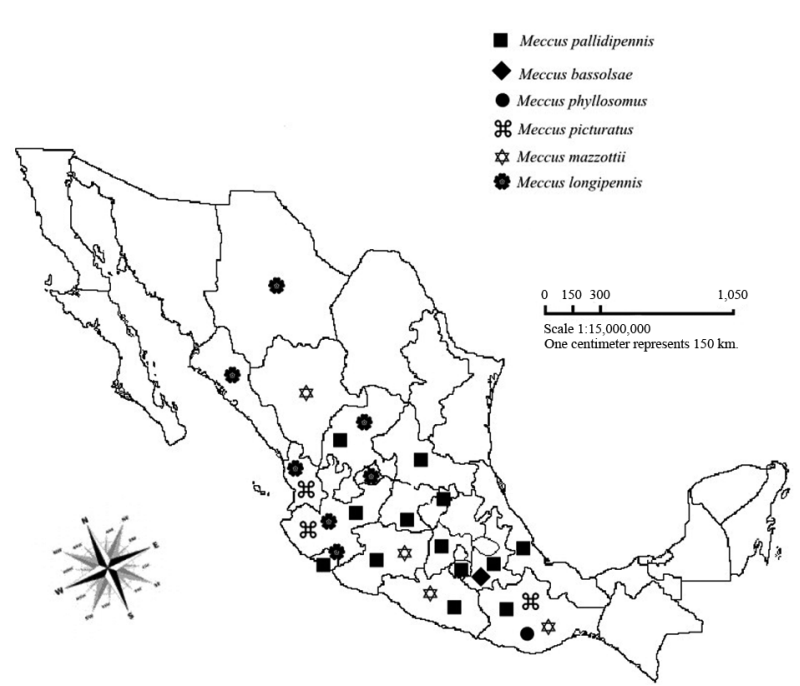

Fig. 1: distribution of the species of the Phyllosoma complex in Mexico (based on Dujardin et al. 2002, updated with data from Espinoza-Gómez et al. 2002, Galvão et al. 2003, Martínez-Campos 2003, Martínez-Ibarra et al. 2008).

and only provided data on the first generation (F1) of most sets of crosses and on the first two generations (F1 and F2) of the set of crosses between M. mazzottii and $M$. longipennis. More recently, Martínez-Ibarra et al. (2005) have reported natural fertile hybrids from $M$. pallidipennis and $M$. longipennis as well as from $M$. pallidipennis and $M$. picturatus in the wild, establishing a low degree of reproductive isolation among these three species of the genus Meccus. These studies, showing biological evidence for the low degree of reproductive isolation among these four species of the genus Meccus, have been enhanced by recent molecular studies (Bargues et al. 2000, Marcilla et al. 2001, Martínez et al. 2006) that support the proposition that six species of the Phyllosoma complex (including M. phyllosomus and $M$. bassolsae) should be considered as subspecies. On the other hand, other molecular studies (Sainz et al. 2004, Pfeiler et al. 2006) consider these species as valid ones. Since this debate has continued, knowledge about the degree of reproductive isolation of species of the Phyllosoma complex still needs to be improved.

Therefore, within the framework of the research on the Phyllosoma complex in Mexico, this study was conducted to determine the degree of reproductive isolation of some of these species, and to gather additional information for the appropriate level for their taxonomical assignment.

\section{MATERIALS AND METHODS}

Crosses between species from non-overlapping areas under laboratory conditions - The specimens used in these crosses were obtained from colonies established for at least six generations with Triatominae from nonoverlapping areas. This procedure guarantees the colonies' purity with regard to the exclusion of previous interfertility events. The five colonies used in the experiments comprised four of the most widely distributed species of the Phyllosoma complex plus M. bassolsae, a species that has scarcely been studied (Alejandre-Aguilar et al. 1999, Martínez et al. 2006, Martínez-Ibarra et al. 2006). Colo- nies started as follows: in the case of $M$. pallidipennis, 30 specimens were collected in Amilzingo, Morelos (18 $\left.50^{\prime} \mathrm{N} 98^{\circ} 49^{\prime} \mathrm{W}\right)$; for $M$. picturatus, there were 43 specimens from Jala, Nayarit $\left(104^{\circ} 26^{\prime} \mathrm{N} 21^{\circ} 03^{\prime} \mathrm{W}\right)$; for M. longipennis, 95 specimens were collected from Teocuitatlán de Corona, Jalisco $\left(20^{\circ} 06^{\prime} \mathrm{N} 103^{\circ} 21^{\prime} \mathrm{W}\right)$; for M. mazzottii, 25 specimens were collected in Oaxaca, Oaxaca $\left(17^{\circ} 06^{\prime} \mathrm{N} 96^{\circ} 46^{\prime} \mathrm{W}\right)$; and for M. bassolsae, there were 20 specimens from Acatlán, Puebla $\left(18^{\circ} 10^{\prime} \mathrm{N}\right.$ $\left.96^{\circ} 06^{\prime} \mathrm{W}\right)$. The only overlapping species of Triatominae was Triatoma barberi Usinger, a smaller species. Size differences were considered to prevent the risk of crossing with other complex species. Collected specimens were identified using Lent and Wygodzinsky (1979) keys, and they exhibit the typical morphological characteristics of each species.

For interspecific crosses, ten pairs from each set were placed in plastic jars $(5 \mathrm{~cm}$ diameter $\mathrm{x} 10 \mathrm{~cm}$ height) as follows: (1A) M. mazzottii female and M. longipennis male; (1B) M. mazzottii male and M. longipennis female; (2A) M. mazzottii female and M. picturatus male; (2B) M. mazzottii male and $M$. picturatus female; (3A) M. mazzottii female and M. pallidipennis male; (3B) $M$. mazzottii male and M. pallidipennis female; (4A) $M$. mazzottii female and M. bassolsae male; (4B) M. mazzottii male and M. bassolsae female; (5A) M. longipennis female and $M$. picturatus male; and (5B) M. longipennis male and $M$. picturatus female. The developmental cycle of each parental lineage involved in the study was used as control; most of this data has already been published (Martínez-Ibarra et al. 2003, 2006, Martínez-Ibarra \& Novelo-López 2004). Specimens were maintained within incubators at $27 \pm 1^{\circ} \mathrm{C}$ and $75 \pm 5 \%$ relative humidity and were fed weekly on New Zealand rabbits.

A total of 30 first-instar nymphs from each of the ten crosses of each set were placed in plastic jars (10 per jar). They were fed on rabbit blood until they became adult insects. The first 20 nymphs that reached the 50 instar were sexed and separated into males and females.

Every phenotype was counted and specimens were maintained with weekly blood feedings. Each female was checked daily for eggs. Collected eggs were observed for at least 25 days in order to check their viability. Viable offspring were maintained up to the adult stage.

Crosses between F1 individuals - In order to determine the fertility of the F1 offspring originating from crosses involving the five species described in this study, five females and five males of each type were crossed. Once second generation (F2) were obtained, phenotype segregation, viability and fertility were determined. The experimental order of crosses was five $\mathrm{F} 1$ females $\mathrm{x}$ five sibling F1 males. Again, 30 first-instar nymphs (assuming that there were at least 20 adults, given mortality rates) from each of the crosses from each set were placed in plastic jars (10 per jar). Nymphs were similarly fed on rabbit blood until they reached the adult phase. Following this, the offsprings' phenotype was described. Likewise, to determine the fertility index of the F2, five F2 females and five sibling F2 males were crossed. As soon as the first-instar nymphs were obtained, and F2 fertility was proved, the couples were discarded. 
On the other hand, male or female specimens involved in F1 x F1 crosses that produced no F2 progeny were backcrossed with specimens (apparently dominant) of the M. mazzottii parental lineage, in order to verify whether they were fertile (Southwood \& Henderson 2000). If no offspring were obtained, they were backcrossed with specimens of the other parental lineage.

\section{RESULTS}

The percentage of success (couples with offspring) was above $50 \%$ in most parental crosses. The highest value was obtained in crosses between $M$. longipennis females and $M$. picturatus males, and the lowest in those between M. mazzottii males and M. picturatus females (Table I).

The morphological characteristics listed in the keys (pronotum withrounded humeral angles, more than $25 \mathrm{~mm}$ in length, strongly widened abdomen, abundant pilosity, first antennal segment reaching or surpassing the level of apex of clypeus, spongy fossulae absent in both sexes) were present in all F1 hybrid specimens, i.e., offspring originating from crosses between "pure" (parental) species.

F1 hybrids had specific morphological characteristics. As a result, they were identified according the following criteria:

Phenotypes of F1 offspring from crosses between M. mazzottii and M. longipennis - All F1 offspring obtained from crosses between M. mazzottii females and $M$. longipennis males were morphological hybrids (described below), while almost half of $\mathrm{F} 1$ offspring from crosses between M. mazzottii males and M. longipennis females presented their male parental phenotype (M. mazzottii); the others were morphological hybrids (Table II). All these specimens were fertile.

Phenotypes of F2 offspring - All F2 offspring from crosses between M. mazzottii and M. longipennis (regardless the parental species) presented morphological characteristics that are typical of M. mazzottii (Table III). The previously described fertility test found that all F2 males were infertile.

Morphological hybrids from M. mazzottii and M. longipennis - These hybrids presented corium without ex-
TABLE I

Percentages of successful crosses (with offspring) between species of the Phyllosoma complex, under laboratory conditions

\begin{tabular}{|c|c|}
\hline Parents & $\begin{array}{l}\text { Successful F1 } \\
\text { crosses (\%) }\end{array}$ \\
\hline † M. mazzottii $\mathrm{x} \delta$ M. longipennis & 60 \\
\hline$\widehat{O}$ M. mazzottii $\mathrm{x}$ q $M$. longipennis & 40 \\
\hline + M. mazzottii x $\widehat{\partial}$ M. picturatus & 80 \\
\hline ô. Mazzottii $\mathrm{x}$ 早 M. picturatus & 20 \\
\hline + M. mazzottii $\mathrm{x} \stackrel{\wedge}{\curvearrowright}$. pallidipennis & 40 \\
\hline o M. mazzottii $\mathrm{x}+$ M. pallidipennis & 40 \\
\hline † M. mazzottii x ô M. bassolsae & 60 \\
\hline ô M. mazzottii $\mathrm{x}$ + M. bassolsae & 60 \\
\hline † M. longipennis x $\curvearrowright$ M. picturatus & 100 \\
\hline o M. longipennis $\mathrm{x}+\mathrm{q}$ M. picturatus & 80 \\
\hline
\end{tabular}

tensive white area, largely black with yellow or orangered markings basally and subapically (similar to both parents). They also presented long, delicate, suberected hairs, about $0.5 \mathrm{~mm}$ in length; long hemelytra extending or almost extending to the abdomen apex (similar to M. mazzottii); dark brown or black connexivum with yellow or orange-red irregularly shaped markings adjoining the abdominal margin and extending to or not extending to the connexival suture (similar to M. longipennis). The posterior lobe of the pronotum was entirely black (similar to both parents) (Fig. 2).

Phenotypes of F1 offspring from crosses between M. mazzottii and M. picturatus - Almost half of F1 offspring from crosses between M. mazzottii males and M. picturatus females, as well as the F1 offspring obtained from backcrosses, presented the M. mazzottii phenotype, while the other half were morphological hybrids (Table II). All F1 specimens were fertile.

Phenotypes of F2 offspring - Not a single specimen was obtained (Table III). To determine whether F1 adults were fertile, they all were individually backcrossed with adults from the M. mazzottii parental lineage. All F1 females thus tested laid fertile eggs, from which numerous

TABLE II

Phenotypes of the first generation derived from crosses between species of the Phyllosoma complex, under laboratory conditions

\begin{tabular}{|c|c|c|c|c|c|c|c|c|c|c|c|c|c|}
\hline \multirow[b]{2}{*}{ Crosses } & \multicolumn{2}{|c|}{$\mathrm{Mm}$} & \multicolumn{2}{|c|}{$\begin{array}{c}\text { Hybrid Mm } \\
\text { x Ml }\end{array}$} & \multicolumn{2}{|c|}{$\begin{array}{c}\text { Hybrid Mm } \\
\text { x Mpi }\end{array}$} & \multicolumn{2}{|c|}{$\begin{array}{c}\text { Hybrid Mm } \\
\text { x Mp }\end{array}$} & \multicolumn{2}{|c|}{$\mathrm{Mp}$} & M1 & \multicolumn{2}{|c|}{ Mpi } \\
\hline & 우 & $\hat{\sigma}$ & 우 & $\hat{0}$ & q & $\hat{0}$ & 우 & $\hat{0}$ & q & $\sigma^{\lambda}$ & + $\hat{0}$ & & $\hat{0}$ \\
\hline q M. mazzottii x $\widehat{o}$ M. longipennis & - & - & 19 & 41 & - & - & - & - & - & - & $-\quad-$ & - & - \\
\hline o M. mazzottii $\mathrm{x}+$ M. longipennis & 13 & & 12 & 10 & - & - & - & - & - & - & & - & - \\
\hline q M. mazzottii x $\widehat{\jmath} M$. picturatus & & 21 & - & - & - & - & - & - & - & - & & - & - \\
\hline$\widehat{\partial}$ M. mazzottii $\mathrm{x}+$ Q M. picturatus & 7 & 3 & - & - & 5 & 5 & - & - & - & - & $-\quad-$ & - & - \\
\hline ㅇ M. mazzottii $\mathrm{x} \widehat{\diamond}$ M. pallidipennis & - & - & - & - & - & - & 22 & 18 & - & - & & - & - \\
\hline o M. mazzottii $\mathrm{x}$ q M. pallidipennis & & & - & - & - & - & 21 & 19 & - & - & $-\quad-$ & - & - \\
\hline ㅇ M. mazzottii x ô M. bassolsae & & & - & - & - & - & - & - & - & - & & - & - \\
\hline ơ M. mazzottii x + M. bassolsae & & 17 & - & - & - & - & - & - & - & - & & - & - \\
\hline ૧ M. longipennis x $\widehat{\delta} M$. picturatus & - & - & - & - & - & - & - & - & - & - & 1614 & & 33 \\
\hline o M. longipennis $\mathrm{x}$ + $M$. picturatus & - & - & - & - & - & - & - & - & - & - & 1418 & & 25 \\
\hline
\end{tabular}

Ml: Meccus longipennis; Mm: Meccus mazzottii; Mp: Meccus pallidipennis; Mpi: Meccus picturatus. 
TABLE III

Phenotypes of the second generation derived from crosses between species of the Phyllosoma complex, under laboratory conditions

\begin{tabular}{|c|c|c|c|c|c|c|c|}
\hline \multirow[b]{2}{*}{ Parental Crosses } & \multirow[b]{2}{*}{ F1 x F1 Crosses } & \multicolumn{2}{|c|}{$\mathrm{Mm}$} & \multicolumn{2}{|c|}{ Ml } & \multicolumn{2}{|c|}{ Mpi } \\
\hline & & 우 & $\hat{\sigma}$ & q & $\hat{\sigma}$ & o & $\hat{\sigma}$ \\
\hline 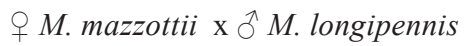 & (Hybrid Mm x Ml) x (Hybrid Mm x Ml) & 25 & 17 & - & - & - & - \\
\hline$\hat{o}$ M. mazzottii $\mathrm{x}$ q M. longipennis & (Hybrid Mm x Ml) x (Hybrid Mm x Ml) & 38 & 31 & - & - & - & - \\
\hline ㅇ M. mazzottii $\mathrm{x} \hat{\jmath}$ M. picturatus & M. mazzottii x M. mazzottii & - & - & - & - & - & - \\
\hline & (Hybrid Mm x Mpi) x (Hybrid Mm x Mpi) & - & - & - & - & - & - \\
\hline o M. mazzottii $\mathrm{x}$ 早 M. picturatus & M. mazzottii x M. mazzottii & - & - & - & - & - & - \\
\hline & (Hybrid Mm x Mpi) x (Hybrid Mm x Mpi) & - & - & - & - & - & - \\
\hline ○ M. mazzottii $\mathrm{x} \precsim$ M. pallidipennis & (Hybrid Mm x Mp) x (Hybrid Mm x Mp) & - & - & - & - & - & - \\
\hline o. Mazzottii $\mathrm{x}$ q $M$. pallidipennis & (Hybrid Mm x Mp) x (Hybrid Mm x Mp) & - & - & - & - & - & - \\
\hline ○ M. mazzottii x §ิ M. bassolsae & M. mazzottii x M. mazzottii & - & - & - & - & - & - \\
\hline o. mazzottii x + M. bassolsae & M. mazzottii x M. mazzottii & - & - & - & - & - & - \\
\hline 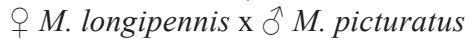 & M. picturatus x $M$. picturatus & - & - & 19 & 20 & 56 & 53 \\
\hline & M. longipennis $\mathrm{x} M$. longipennis & - & - & 69 & 100 & 10 & 5 \\
\hline$\widehat{o}$. longipennis $\mathrm{x}$ + $M$. picturatus & M. picturatus x $M$. picturatus & - & - & 9 & 9 & 34 & 26 \\
\hline & M. longipennis $\mathrm{x}$ M. longipennis & - & - & 15 & 50 & 8 & 5 \\
\hline
\end{tabular}

M1: Meccus longipennis; Mm: Meccus mazzottii; Mp: Meccus pallidipennis; Mpi: Meccus picturatus.

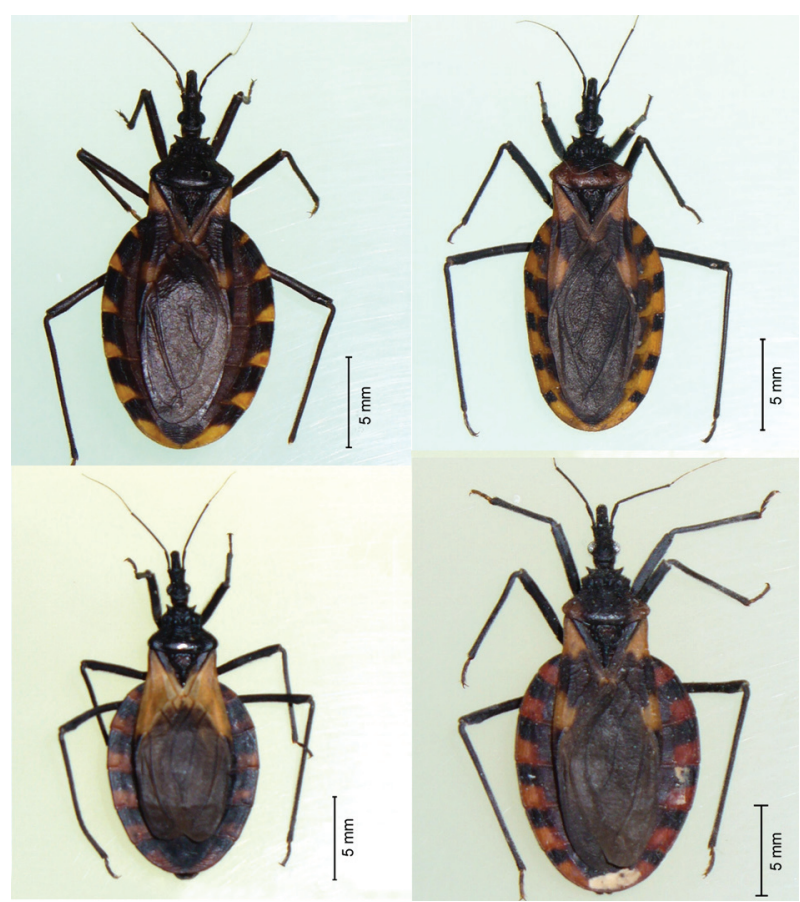

Fig. 2: hybrids from different crosses between species of the Phyllosoma complex (clock wise, beginning top left): M. mazzottii x M. longipennis, M. mazzottii x M. picturatus, M. mazzottii x M. bassolsae, $M$. mazzottii x M. pallidipennis.

first-instar nymphs were obtained. On the other hand, plenty of mating events and spermatophore eliminations by females were observed when F1 male hybrids were crossed with virgin females of $M$. mazzottii, but all the eggs were infertile. As a second step, virgin females of the other parental lineage ( $M$. picturatus) were individually put together with each male being tested. Once again, although plenty of copulative events and spermatophore eliminations were recorded in all couples, all the eggs were infertile. To be sure that all males were infertile, all females used in the fertility test were crossed with parental lineage males. Fertile eggs as well as first-instar nymphs were obtained, and the apparent infertility of male hybrids was confirmed.

Morphological hybrids of M. mazzottii and M. picturatus - These hybrids presented corium without extensive white area, largely black with yellow or orangered markings basally and subapically (similar to both parents). They also presented long, delicate, suberected hairs about $0.5 \mathrm{~mm}$ in length, long hemelytra extending or almost extending to the abdomen apex, and connexivum with orange-red spots dorsally covering the entire posterior third to half of segments (similar to M. mazzottii). The posterior lobe of the pronotum was extensively orange-yellow (similar to M. picturatus) (Fig. 2).

Phenotypes of F1 offspring from crosses between $M$. mazzottii and M. pallidipennis - All F1 offspring originating from crosses between M. mazzottii and M. pallidipennis, as well as the F1 progeny of backcrosses, were morphological hybrids (Table II). All these F1 specimens proved to be fertile.

Phenotypes of F2 offspring - Not a single specimen was obtained (Table III). Like the F1 descendants of $M$. mazzottii and $M$. picturatus, all F1 adults were individually backcrossed with adults of the $M$. mazzottii parental lineage for testing fertility. All F1 females tested laid fertile eggs, from which a large number of first-instar nymphs were obtained. On the other hand, although many copulative events and spermatophore eliminations by females were recorded during the tests with F1 males and virgin females of $M$. mazzottii, all the eggs laid were infertile. Once again, a second test was carried out, in which virgin females of the other parental lineage $(M$. pallidipennis) were individually put together with each male being tested. As in the previously described crosses, although many copulative events and spermatophore eliminations by females were recorded in all couples, all 
the eggs laid by females were infertile. To be sure that all these males were infertile, all females involved in the fertility test were crossed with males of the parental lineage. Fertile eggs as well as first-instar nymphs were obtained, and the supposed infertility of these male hybrids was then confirmed.

Morphological hybrids of M. mazzottii and M. pallidipennis - These hybrids presented a corium that was largely yellowish white with orange basally and black apically (similar to M. pallidipennis). They also presented long, delicate, suberected hairs about $0.5 \mathrm{~mm}$ in length, long hemelytra extending or almost extending to the abdomen apex, and connexivium with orangered spots dorsally covering the entire posterior third to half of segments (similar to M. mazzottii). The posterior lobe of the pronotum was entirely black (similar to both parents) (Fig. 2).

Phenotypes of $\mathrm{Fl}$ offspring from crosses between M. mazzottii and M. bassolsae - All F1 offspring of crosses between M. mazzottii male and M. bassolsae female, as well as the F1 progeny of backcrosses, had the phenotype of M. mazzottii (Table II). Fertility tests conducted on all these F1 specimens indicated they were fertile.

Phenotypes of F2 offspring - Not a single specimen was obtained (Table III). The same procedure described above was performed, with similar results: all F1 females tested laid fertile eggs, from which numerous first-instar nymphs were obtained, while only infertile eggs were obtained (in a second step) from backcrosses between F1 males and virgin females of M. mazzottii, as well as F1 males and virgin females of M. bassolsae. Finally, all the females used in the fertility test were crossed with parental lineage males. Fertile eggs as well as first-instar nymphs were obtained, and these male hybrids were, therefore, considered infertile.

Non-morphological hybrids of M. mazzottii and M. bassolsae - These hybrids presented a corium without extensive white area, largely black with yellow or orange-red markings basally and subapically (similar to both parents). They also presented long, delicate, suberected hairs about $0.5 \mathrm{~mm}$ in length, long hemelytra extending or almost extending to abdomen apex, and connexivum with orange-red spots dorsally covering the entire posterior third to half of segments (similar to $M$. mazzottii). The posterior lobe of the pronotum was entirely black (similar to both parents) (Fig. 2).

Phenotypes of F1 offspring from crosses between $M$. longipennis and M. picturatus - Two phenotypes $(M$. longipennis and $M$. picturatus) were obtained from these crosses, regardless of parent species (Table II). The test proved that all $\mathrm{F} 1$ specimens were fertile.

Phenotypes of F2 offspring - Once again, two phenotypes (M. longipennis and M. picturatus) were obtained from these crosses, regardless of parental species (Table III). As described previously, F2 x F2 crosses were conducted and progeny was obtained.

Non-morphological hybrids of M. longipennis and M. picturatus - Two phenotypes of non-morphological hybrids were obtained, both with corium without extensive white area, largely black with yellow or orange-red markings basally and subapically, with short, slightly decumbent or adpressed setae not more than $0.3 \mathrm{~mm}$ long (similar to both parents). Non-morphological hybrids were similar to $M$. longipennis and presented a pronotum with a posterior lobe entirely black or with $1+1$ small, light-colored spots on the humeri; whereas non-morphological hybrids, similar to M. picturatus, presented an intensely orange-yellow posterior lobe of the pronotum (Fig. 3).

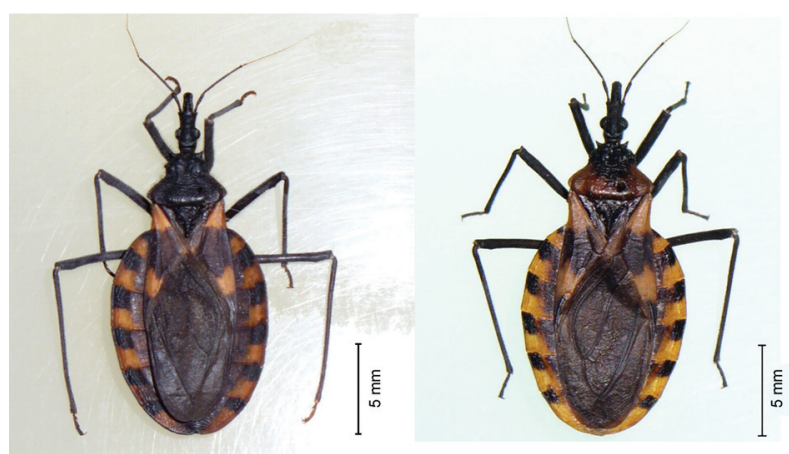

Fig. 3: hybrids from crosses between $M$. longipennis x M. picturatus: phenotype of $M$. longipennis (left), phenotype of $M$. picturatus (right).

\section{DISCUSSION}

Studies on hybridization are extraordinarily powerful tools for analyzing phenomena that may lead a population to divergence and speciation (for example, the formation of isolating mechanisms). Although the results of experimental crosses under laboratory conditions can be biased, since organisms of different "species" are forced (breaking all ecological, behavioral and geographical barriers) to live together, these kinds of studies may help in understanding the systematics of a group (Pérez et al. 2005).

In our study, successful results (couples with offspring) in each type of cross seem to be correlated to the distance between species in some phylogenetic trees (Flores et al. 2001, Marcilla et al. 2001, Martínez et al. 2006). The most successful crosses were those that occurred between phylogenetically closer species, such as $M$. longipennis and $M$. picturatus, which have been sympatrically collected in Western Mexico. On the other hand, the least successful crosses occurred between species less phylogenetically related (Marcilla et al. 2001, Martínez et al. 2006, Pfeiler et al. 2006), such as between M. mazzottii and M. pallidipennis, M. longipennis and M. picturatus, which have been allopatrically collected. These phenomena have been previously recorded in a series of studies (Perlowagora-Szumlewicz \& Correia 1972, Perlowagora-Szumlewicz et al. 1974, Perlowagora-Szumlewicz 1976) on South American Triatominae species' hybridization, which came to the conclusion that viable reciprocal crosses (male of one species with female of another, and vice versa) between Triatoma pseudomaculata Corrêa \& Espínola and Triatoma sordida Stål demonstrated genetic proximity between these 
two species, whereas unilateral crosses (successful in only one direction, male of one species and female of the other, or vice versa) demonstrated more distant relationships, as between T. pseudomaculata and Triatoma infestans Klug.

The ease with which M. mazzottii and three of the studied species (M. pallidipennis, M. picturatus, M. bassolsae) intercrossed in the laboratory, despite the lack of fertile hybrids having been collected in nature, may be explained by the fact that they seem to be parapatric species (Fig. 1), at least in the areas where the exemplars used in this study were collected. As they do not coexist, there would be no features selection (either morphological or behavioral) that could lead to a reproductive isolation between them. This type of behavior has also been recorded for Triatoma maculata Erichson and T. pseudomaculata from Brazil (Belisário et al. 2007).

As for the percentage of couples with offspring, the capacity to produce a F2 also seemed to be influenced by the phylogenetic distance between the species, since three sets of crosses involving specimens of less phylogenetically related species (M. mazzottii x M. pallidipennis, M. mazzottii x M. picturatus and M. mazzottii x M. bassolsae) did not produce a single F2 descendant in crosses between F1 individuals. This is probably due to the infertility of male hybrids F1, as reported earlier in crosses between M. mazzottii and M. longipennis (Zárate et al. 1985) and in crosses between T. infestans and Triatoma rubrovaria Blanchart (Pérez et al. 2005). Similarly, even when crosses between M. mazzottii and M. longipennis did produce a second generation, all F2 males were infertile, showing their degree of reproductive isolation. Those phenomena were similar to that described in Costa et al. (2003), where four morphologically different populations of Triatoma brasiliensis Neiva (brasiliensis, melanica, macromelanosoma and juazeiro) were crossed in order to evaluate their genetic and reproductive compatibility. This paper recorded low compatibility levels between brasiliensis and melanica, which became even lower when a melanica female was in the cross, similar to our work where lower compatibility levels were recorded between M. mazzottii and $M$. picturatus, mainly when the female was from the $M$. picturatus species.

On the other hand, crosses between M. longipennis and M. picturatus had F1, F2 and even third generation progeny, indicating a low degree of reproductive isolation between these species. This could be correlated with the phylogenetic proximity between these two species, which has been previously established in most related molecular studies (Bargues et al. 2000, Flores et al. 2001, Marcilla et al. 2001, Martínez et al. 2006, Pfeiler et al. 2006) by using exemplars of $M$. picturatus from two states (Jalisco and Nayarit) and of M. longipennis from four states (Jalisco, Nayarit, Colima and Zacatecas) in Western Mexico.

All F1 offspring from crosses involving M. mazzottii, as well as the F2 progeny from F1 crosses between descendants of M. mazzottii x M. longipennis present most of the M. mazzottii's typical characteristics, as did the previously reported specimens originating from crosses between M. mazzottii and M. picturatus, M. mazzottii and M. pallidipennis, and M. mazzottii and M. longipennis (Mazzotti \& Osorio 1942, Zárate et al. 1985).

Taking into account the present results, it seems there are different degrees of reproductive isolation between the species of the Phyllosoma complex involved in this study. The species less phylogenetically related, such as M. mazzottii with respect to M. pallidipennis, M. picturatus and $M$. bassolsae, were reproductively more isolated. On the other hand, M. longipennis appears to have a moderate degree of reproductive isolation with respect to M. mazzottii, as suggested previously (Zárate et al. 1985), and a low degree in relation to M. picturatus. A possible reason may be the fact that $M$. longipennis and M. picturatus are phylogenetically closer to each other than M. mazzottii is to any of the other studied species (Bargues et al. 2000, Flores et al. 2001, Marcilla et al. 2001, Martínez et al. 2006). Another reason is the existence of a correlation between geographic distance and degree of reproductive isolation, since the species that have been collected parapatrically in various areas, such as M. longipennis and M. picturatus (Martínez-Ibarra et al. 2001, 2008, Magallón-Gastélum 2006), M. pallidipennis and $M$. longipennis, and $M$. pallidipennis and M. picturatus, presented lower degrees of reproductive isolation (Martínez-Ibarra et al. 2005). Similar results were reported when four morphologically different T. brasiliensis populations were studied; having lower degrees of reproductive isolation, those populations (brasiliensis and macromelanosoma) were collected from geographically close areas (Costa et al. 2003). Likewise, the relationship between $M$. longipennis and M. mazzottii can not be explained, since they have rarely been collected parapatrically, though they are phylogenetically close.

According to the species concept proposed by Dobzhansky (1937), "a species is a group of fully fertile individuals, reproductively isolated from other similar groups due to their physiological features (producing parental incompatibility, hybrid sterility, or both)". Similarly, the biological species concept states that "a species is a group of interbreeding natural populations that is reproductively isolated from other such groups" (Mayr $\&$ Ashlock 1991). In accordance with this latter concept, in light of some previously published works (Flores et al. 2001, Martínez et al. 2005, 2006, Takashi-Obara et al. 2007), M. picturatus, M. pallidipennis and M. longipennis (species collected previously in sympatric occurrence) could be considered subspecies of M. phyllosomus. Also, biological evidence found in this study could support the proposition that it is more appropriate to attribute a subspecies level to both $M$. longipennis and M. picturatus, as proposed in the case of $M$. pallidipennis (Martínez-Ibarra et al. 2005). On the other hand, the same biological evidence recorded in the present study does support the proposal that M. mazzottii is a full species, as some recent molecular studies have proposed (Saintz et al. 2004, Pfieiler et al. 2006). Therefore, it is necessary to develop further research focusing on the Phyllosoma complex, particularly on crosses involving the rest of the species, since information gathered in some earlier studies (Martínez et al. 2005, 2006) sug- 
gests that these species have recent evolutionary relationships and probably reflect a divergence in a common ancestor, representing a monophyletic group (TakashiObara et al. 2007).

Although the current study has increased our knowledge about the degrees of reproductive isolation among some species of the Phyllosoma complex, which could contribute to the proper taxonomic status of the members of the Phyllosoma complex, it seems that the debate will continue. New studies using longer mtDNA sequences than that used in the related studies (Marcilla et al. 2001, Martínez et al. 2006, Pfeiler et al. 2006) or using other more accurate genetic markers need to be carried out in order to shed light on this topic.

\section{ACKNOWLEDGEMENTS}

To Yunuen Grant-Guillén for helping in the development of this study. To Guillermo Espinosa for helping on take the pictures of triatomines. To Marcia Chaves Souza for helping on improve the English presentation.

\section{REFERENCES}

Alejandre-Aguilar R, Nogueda-Torres B, Cortés-Jiménez M, Jurberg J, Galvão C, Carcavallo R 1999. Triatoma bassolsae sp. n. do Mexico, com uma chave para as especies do complexo "phyllosoma" (Hemiptera: Reduviidae). Mem Inst Oswaldo Cruz 94: 353-359.

Bargues MD, Marcilla A, Ramsey JM, Dujardin JP, Schofield CJ, Mas-Coma S 2000. Nuclear rDNA-based molecular clock of the evolution of Triatominae (Hemiptera: Reduviidae), vectors of Chagas disease. Mem Inst Oswaldo Cruz 95: 567-573.

Belisário CJ, D’Ávila Pessoa GC, Diotaiuti L 2007. Biological aspects of crosses between Triatoma maculata (Erichson, 1848) and Triatoma pseudomaculata Corrêa \& Espínola, 1964 (Hemiptera: Reduviidae). Mem Inst Oswaldo Cruz 102: 517-521.

Carcavallo R, Jurberg J, Lent H, Noireau F, Galvão C 2000. Phylogeny of the Triatominae (Hemiptera: Reduviidae). Proposal for taxonomic arrangements. Entomol Vect 7: 1-99.

Cohen JM, Wilson ML, Cruz-Celis A, Ordóñez R, Ramsey JM 2006. Infestation by Triatoma pallidipennis (Hemiptera: Reduviidae: Triatominae) is associated with housing characteristics in rural Mexico. J Med Entomol 43: 1252-1260.

Costa J, Almeida CE, Dujardin JP, Beard CB 2003. Crossing experiments detect genetic imcompatibility among populations of Triatoma brasiliensis Neiva, 1911 (Heteroptera, Reduviidae, Triatominae). Mem Inst Oswaldo Cruz 97: 25-30.

Dobzhansky T 1937. Genetics and the origin of species, Columbia Univ Press, New York, 147 pp.

Dujardin JP, Schofield CJ, Panzera F 2002. Taxonomía de los Triatominae. In JP Dujardin, CJ Schofield, F Panzera (eds), Los vectores de la enfermedad de Chagas, Academie Royale des Sciences D'outre-mer, Koninklijke Academie Voor Overzeese Wetenschappen, Brussels, p. 25-64.

Espinoza-Gómez F, Maldonado-Rodríguez A, Coll-Cárdenas R, Hernández-Suárez CM, Fernández-Salas I 2002. Presence of Triatominae (Hemiptera: Reduviidae) and risk of transmission of Chagas disease in Colima, México. Mem Inst Oswaldo Cruz 97: 25-30.

Flores A, Magallón-Gastélum E, Bosseno MF, Ordóñez R, LozanoKasten F, Espinoza B, Ramsey JM, Breniere SF 2001. Isoenzyme variability of five principal triatomine vector species of Chagas disease in Mexico. Infect Genet Evol 4: 1-8.

Galvão C, Carcavallo R, Rocha-Da Silva D, Jurberg J 2003. A checklist of the current valid species of the subfamily Triatiominae Jeannel, 1919 (Hemiptera: Reduviidae) and their geographical distribution, with nomenclatural and taxonomic notes. Zootaxa 202: 1-36.

Lent H, Jurberg J, Galvão C 1994. Revalidação do gênero Mepraia Mazza, Gajardo \& Jöerg, 1940 (Hemiptera, Reduviidae, Triatominae). Mem Inst Oswaldo Cruz 89: 347-352.

Lent H, Wygodzinsky P 1979. Revision of the triatominae (Hemiptera: Reduviidae) and their significance as vectors of Chagas disease. Bull Am Mus Nat Hist 163: 123-520.

Magallón-Gastélum E, Lozano-Kasten F, Gutiérrez MS, Flores-Pérez A, Sánchez B, Espinoza B, Bosseno MF, Breniere SF 2006. Epidemiological risk for Trypanosoma cruzi by species of Phyllosoma complex in the occidental part of Mexico. Acta Trop 97: 331-338.

Marcilla A, Bargues MD, Ramsey JM, Magallón-Gastélum E, Salazar-Schettino PM, Abad-Franch F, Dujardin JP, Schofied CJ, Mas-Coma S 2001. The ITS-2 of the nuclear rDNA as a molecular marker for populations, species, and phylogenetic relationships in Triatominae (Hemiptera: Reduviidae), vector of Chagas disease. Mol Phylogenet Evol 18: 136-142.

Martínez-Campos C 2003. Conocimiento actual sobre la distribución de los triatominos en México. In JM Ramsey, A Tello, JL Pohls (eds), Iniciativa para la vigilancia y el control de la enfermedad de Chagas en la República Mexicana, Instituto Nacional de Salud Pública, México, p. 108-109.

Martínez F, Alejandre-Aguilar R, Hortelano-Moncada Y, Espinoza B 2005. Molecular taxonomic study of Chagas disease vectors from the Phyllosoma, Lecticularia and Rubrofasciata complexes. Am J Trop Med Hyg 73: 321-325.

Martínez HF, Villalobos CG, Ceballos AM, De la Torre P, Laclette JP, Alejandre-Aguilar R, Espinoza B 2006. Phylogenetic analysis of Triatominae (Hemiptera : Reduviidae) species of epidemiological importance in the transmission of Chagas disease: nuclear DNA vs mitochondrial DNA as molecular markers. Mol Phylogenet Evol 41: 279-287.

Martínez-Ibarra JA, Alejandre-Aguilar R, Torres-Morales A, Trujillo-García JC, Nogueda-Torres B, Trujillo-Contreras F 2006. Biology of three species of the Meccus phyllosomus complex (Hemiptera: Reduviidae Triatominae) fed on blood of hens and rabbits. Mem Inst Oswaldo Cruz 101: 787-794.

Martínez-Ibarra JA, Bárcenas-Ortega NM, Nogueda-Torres B, Alejandre-Aguilar R, Rodríguez ML, Magallón-Gastélum E, López-Martínez V, Romero-Nápoles J 2001. Role of two Triatoma (Hemiptera: Reduviidae: Triatominae) species in the transmission of Trypanosoma cruzi (Kinetoplastida: Trypanosomatidae) to man in the West coast of Mexico. Mem Inst Oswaldo Cruz 96: 141-144.

Martínez-Ibarra JA, Grant-Guillén Y, Morales-Corona Z, Haro-Rodriguez S, Ventura-Rodríguez LV, Nogueda-Torres B, BustosSaldaña R 2008. Importance of species of Triatominae (Heteroptera, Reduviidae) in the risk of transmission of Trypanosoma cruzi in Western Mexico. J Med Entomol 45: 476-482.

Martínez-Ibarra JA, Morales-Corona ZY, Moreno-Ruiz MG, Del Riego-Ruiz R, Mundo-Barajas MA 2005. Híbridos naturales y fértiles entre especies del complejo Meccus phyllosomus (Hemiptera: Reduviidae) en Jalisco, México. Entomol Mex 4: 734-738.

Martínez-Ibarra JA, Novelo-López M 2004. Biological parameters of Triatoma pallidipennis Stal (Hemiptera: Reduviidae) under laboratory conditions. Folia Entomol Mex 43: 313-319.

Martínez-Ibarra JA, Novelo-López M, Hernández-Robles MR, GrantGuillén Y 2003. Influence of the blood meal source on the biology of Meccus picturatus Usinger 1939 (Hemiptera: Reduviidae: Triatominae) under laboratory conditions. Mem Inst Oswaldo Cruz 98: 227-232. 
Mayr E, Ashlock PD 1991. Principles of systematic Zoology, McGrawHill, New York, 475 pp.

Mazzotti L 1943. Triatoma phyllosoma usingeri, a new subspecies of Triatoma from Mexico. Pan Pac Entomol 19: 80-85.

Mazzotti L, Osorio MT 1942. Cruzamientos experimentales entre varias especies de triatomas. Rev Mex Med 22: 215-222.

Pérez R, Hernández M, Quintero O, Scvortzoff E, Canale D, Méndez L, Cohanoff C, Martino M, Panzera F 2005. Cytogenetic analysis of experimental hybrids in species of Triatominae (HemipteraReduviidae). Genetica 125: 261-270.

Perlowagora-Szumlewicz A 1976. Male sterility induced through interespecific hybridation of Triatominae. XV Internacional Congress Entomology, Washington, D.C., p. 1-824.

Perlowagora-Szumlewicz A, Correia MV 1972. Introduction of male sterility though manipulation of genetic mechanism present in vector species of Chagas' disease. Rev Inst Med Trop São Paulo 14: $360-371$

Perlowagora-Szumlewicz A, Correia MV, Trinxet AMR 1974. Introduction of male sterility II: onset of disappearance of induced sterility in successive backcrosses. Proc of Munich, FR Germany, p. 25-31.

Pfeiler E, Bitler BG, Ramsey JM, Palacios-Cardiel C, Markow TA 2006. Genetic variation, population structure, and phylogenetic relationships of Triatoma rubida and T. recurva (Hemiptera: Reduviidae: Triatominae) from the Sonoran desert, insect vectors of the Chagas' disease parasite Trypanosoma cruzi. Mol Phylogenet Evol 41: 209-221.
Sainz AC, Mauro LV, Moriyama EN, García BA 2004. Phylogeny of triatomine vectors of Trypanosoma cruzi suggested by mithocondrial DNA sequences. Genetica 121: 229-240.

Salazar-Schettino PM, De Haro-Arteaga I, Cabrera-Bravo M 2005. Tres especies de triatominos y su importancia como vectores de Trypanosoma cruzi en México. Medicina (B Aires) 65: 63-69.

Silva FP, Schreiber G 1969. Morphology of spermatogenetic tubes as taxonomic character in Triatominae. Rev Brasil Biol 29: 97-102.

Southwood TRE, Henderson PA 2000. Ecological methods, Blackwell Science, Oxford, United Kingdom, 575 pp.

Takashi-Obara M, Soares-Barata JM, Nunes da Silva N, CerettiJúnior W, Urbinatti PR, da Rosa JA, Jurberg J, Galvão C 2007. Estudo do ovos de quarto espécies do genero Meccus (Hemiptera, Reduviidae, Triatominae), vetores da doença de Chagas. Mem Inst Oswaldo Cruz 102: 13-19.

Usinger RL, Wygodzinsky P, Ryckman R 1966. The biosystematics of Triatominae. Annu Rev Entomol 11: 309-330.

Vidal-Acosta V, Ibáñez-Bernal S, Martínez-Campos C 2000. Infección natural de chinches Triatominae con Trypanosoma cruzi asociadas a la vivienda humana en México. Salud Pub Mex 42: 496-503.

Zárate LG, Zárate RJ, Morales-López G, Espinoza-Medinilla E, Cabrera-Ozuna M, García-Santiago G, Castillo-Montoya C, López-Pérez G, Martínez-Icó M, Martner-Peyrelongue D, Tovilla-Hernández C 1985. Estudio epidemiológico de la enfermedad de Chagas en el sureste de México, Centro de Investigaciones Ecológicas del Sureste, Informe de Investigación, México, D.F., 31 pp. 